\title{
Depressive symptoms in patients with epilepsy and clinically associated features in a single tertiary center
}

\author{
Mariacarolina Vacca ${ }^{1}$ (D) Mariana Fernandes ${ }^{2} \cdot$ Matteo Spanetta $^{2} \cdot$ Fabio Placidi $^{2,3} \cdot$ Francesca Izzi $^{3}$. \\ Caterina Lombardo $^{1} \cdot$ Nicola Biagio Mercuri ${ }^{2,3,4} \cdot$ Claudio Liguori $^{2,3}$ (I)
}

Received: 7 May 2021 / Accepted: 26 August 2021 / Published online: 15 September 2021

(C) The Author(s) 2021

\begin{abstract}
Although depressive symptoms are the most common psychiatric comorbidity in epilepsy, they remain underestimated and untreated in a large proportion of patients. The purpose of this study was to evaluate depression severity and related clinical features in people with epilepsy using a well-reliable self-report index of mood, the Beck Depression Inventory-II (BDI-II). Onehundred seventeen adult patients with epilepsy were recruited from a tertiary epilepsy center and completed the BDI-II. A singleitem analysis of the 21 questions of the BDI-II was computed and differences between women and men in each depressive symptom were evaluated. Correlation and regression analyses were used to identify clinical features associated with the severity of depression. Results showed gender differences in some items, with women reporting overall higher depression severity than men. The most common symptoms regarded domains of sleeping patterns, tiredness, and loss of energy. Regression evidence suggested that being female, having an epilepsy duration $<10$ years, as well as being treated with psychotropic drugs and reporting generalized seizure, were associated with higher depression severity. Despite its cross-sectional nature, this study reinforces the importance of investigating and possibly treating depressive symptoms in adult patients with epilepsy, since they negatively impact well-being, daytime activities, and sleep. Further studies identifying pharmacological and nonpharmacological treatments for depression in epilepsy need to be planned.
\end{abstract}

Keywords Depressive symptoms · Generalized seizure · BDI-II; Comorbidity $\cdot$ Adulthood

\section{Introduction}

Epilepsy affects all aged people and results in profound physical and psychopathological consequences [1-3]. Notably, comorbid psychiatric conditions are highly prevalent among patients with epilepsy as compared to the general population [2, $3]$ suggesting that psychiatric illnesses often accompany the diagnosis of epilepsy [4], or even precede the onset of the disease [5]. Moreover, the most common interictal psychiatric

Claudio Liguori

dott.claudioliguori@yahoo.it

1 Department of Psychology, Sapienza University of Rome, Rome, Italy

2 Department of Systems Medicine, University of Rome Tor Vergata, Rome, Italy

3 Epilepsy Center, Neurology Unit, University Hospital of Rome Tor Vergata, Rome, Italy

4 IRCSS Santa Lucia Foudantion, Rome, Italy disease in epilepsy is depression [6]. Accordingly, individuals with epilepsy report significantly elevated odds of depression than those without epilepsy, even after adjusting for potential confounders (e.g., age, gender, comorbid physical illnesses [2]). Among the potential neurobiological determinants, epilepsy-related variables such as duration, frequency and severity of seizures, and medication have been of particular interest [7]. Therefore, previous investigations have attempted to evaluate the association between the aforementioned risk factors and depression in epilepsy.

Despite depression is a frequent psychiatric condition in individuals with epilepsy, its prevalence is often underestimated [8]. This evidence seems particularly alarming when considering that some studies reporting depression may exacerbate epilepsyrelated symptoms (e.g., fatigue, stress, sleep problems) [9, 10] and hinder the positive outcomes of epilepsy treatment [11]. Systematic evidence suggests an overall prevalence of depression of $22.9-23.1 \%$ [12] and a lifetime prevalence for major depression ranging between 8 and $48 \%$ in patients with epilepsy [6]. Depressive symptoms in epilepsy affect patients' well-being 
and the clinical course of the disease [13, 14]. The use of some anti-seizure medications (ASMs) to manage seizures can significantly affect mood by alleviating or exacerbating depressive symptoms [15]. On the other hand, some ASMs (e.g., GABAergic drugs) have been related to the worsening of mood symptoms in epilepsy $[16,17]$.

Predominantly, interest of clinicians focused on identifying valid assessment tools to robustly detect the presence of depressive symptoms among patients with epilepsy [18]. A recent systematic review on the validity of depression-screening tools in epilepsy reports that Beck Depression Inventory (BDI) [19] is a complete instrument to evaluate depressive symptoms in people with epilepsy for screening purposes, as compared to other selfreport scales [20]. Studies employing this inventory, and, in particular, its later version (BDI-II) [21] found that the BDI total score often distinguished depressed from non-depressed participants with epilepsy [22, 23], confirming its well-recognized sensitivity. Some authors employ a single-item analysis approach in order to investigate the distribution of each specific facet assessed through the BDI and its relationship with epilepsy-related aspects [24]. The inspection of the single item provides valuable additional information on the core affective, somatic, and cognitive features of depression among individuals with epilepsy.

Hence, in this study, we investigated depressive symptoms in patients with epilepsy visited in a tertiary clinical center, by using the BDI-II with a single-item approach in order to detect the wide spectrum of depressive symptoms in this population of patients. Moreover, considering that gender may influence the prevalence of depression in epilepsy $[25,26]$, this study aims to compare depressive symptom patterns according to the BDI-II between female and male patients affected by epilepsy. Consistently with previous evidence [25], we expected that depressive symptoms would be more accentuated among female patients. Finally, we investigated the possible influence of seizure type, etiology of epilepsy, monthly total seizure count, and ASMs on depressive symptoms.

\section{Method}

\section{Participants and procedure}

Sample was collected during a 6-month period (from June 2020 to November 2020) with consecutive patients. Participants affected by epilepsy admitted to the Epilepsy Center of the University Hospital of Rome Tor Vergata and diagnosed according to the current clinical criteria suggested by the International League Against Epilepsy were invited to take part to the study. Upon acceptance, all patients were classified according to the recent classification of epilepsy and seizures by three experts in epilepsy (CL, FP, and FI) [27]. All patients underwent a routine neuropsychiatric evaluation involving a full neuropsychiatric history and anamnesis interview according to DSM-IV criteria [28] by a consulting neurologist. The study was approved by the Independent Ethical Committee of the University Hospital of Rome Tor Vergata and all patients gave their written informed consent to participate (R.S. 191/17 - 192/17; Eudract 2017-000990-35). The following demographic and clinical data were analyzed: age, sex, time since epilepsy onset, etiology, 1-month total seizure count, and concomitant ASMs. Inclusion criterion for this study was only age $\geq 18$ years. Exclusion criteria were intellectual disability and/or presence of seizures the day of the outpatient visit.

\section{Instruments}

The BDI-II $[21,29]$ was used to assess depressive symptoms and administered to each patient during a single session on an individual basis. It consists of 21 items with four possible responses, with higher total scores indicative of greater severity of symptoms. Scores ranging from 0 to 13 indicate minimal/no symptoms, 14-19 indicate mild depressive symptoms, 20-28 indicate moderate depressive symptoms, and 2963 indicate severe depressive symptoms. Although these cutoff points have been provided for the general population, many authors have sustained their validity in detecting depression severity among patients with epilepsy [23]. In the present study, the reliability of BDI-II based on McDonald's omega coefficient $(\omega t)$ [30] was high $(\omega t=.901)$ as well as Cronbach alpha coefficient $(\alpha=.898)$, as found in previous studies [31].

\section{Data analysis}

\section{Descriptive statistics and group comparison}

First, descriptive statistics were computed to characterize the sample in terms of gender, age, epilepsy duration, epilepsy type, seizure frequency, seizure type, anti-seizure medication (ASM), and the use of antidepressants and antipsychotic drugs. The normality of the data was assessed through the Shapiro-Wilk test [32]. To minimize false-positive tests of significance, we set a significance level of $p<.01$ [33]. Mann-Whitney $U$ tests were used to examine scores on each items of BDI-II, as did previous authors [34], and to assess the statistical significance of differences in BDI-II scores and item scores between female and male participants. Mann-Whitney $U$ test is a rank-based procedure which is more appropriate with ordinal and not-normally distributed data. Gender comparison was also computed to examine differences in clinical characteristics.

\section{Correlation and regression analyses}

The Tau-Kendall correlation analysis was used to assess the statistical relationships among the variables included in this investigation. The Kendall correlation coefficient [35] is an 
appropriate measure of associations between categorical independent variables (e.g., seizure type) and continuous variables (e.g., BDI-II total score) [36]. Finally, a hierarchical linear regression analysis was computed in order to identify which demographic and clinical characteristic better predicted depressive symptoms severity. A two-stage hierarchical multiple regression was conducted with BDI-II scores as the dependent variable. Independent variables were analyzed separately in two blocks: age and gender in the first block, epilepsy duration, epilepsy type, seizure type, seizure frequency, number of ASM, and number of psychotropic drugs as predictors. Age and BDI total score were entered in the model as continuous variables, while epilepsy duration ( $<12$ months; 13 months10 years; $>10$ years), epilepsy type (structured, unknown), seizure type (unknown, focal, generalized), seizure frequency in the previous month (seizure-free, 1 episode, $\geq 2$ episodes), and number of ASM (1-3) were coded as dummy variables. For this aim, the first category (i.e., epilepsy duration: $<12$ months; seizure type: unknown; seizure frequency: seizurefree; number of ASM: 1) of each of the aforementioned ordinal variable was coded as the reference category. Since there was considerable heterogeneity in epilepsy etiology (see Table 1), the two major classifications (i.e., structured, unknown) were entered in the regression model.

Gender ( 1 = female; $2=$ male $)$ and the use of psychotropic drugs $(0=$ yes; $1=$ no) were coded as dichotomic variables. Data were analyzed using the software program SPSS software version 25.0 [37].

\section{Results}

\section{Description of the sample and prevalence rate of depressive symptoms in single-item analysis}

A total of 117 participants aged 18-84 years were enrolled in the study. Nine patients (7.7\%) did not manage to fill in questionnaires (language difficulties). Demographic and clinical characteristics are displayed in Table 1. Previous routine psychiatric evaluation indicated that five $(4.3 \%)$ and four $(3.4 \%)$ patients experienced anxiety and depression respectively, whereas for three patients $(2.6 \%)$, signs of cognitive delay were observed. As regarding BDI-II scores, forty-two (38.8\%) patients manifested depressive symptoms, with scores greater or equal to 14 . Of those, $19(17.6 \%)$ had mild symptoms (BDI-II scores: 14-19), 13 (12\%) reported moderate symptoms (BDI-II scores: 20-29), and the remaining 10 $(9.3 \%)$ patients had severe symptoms. At the question regarding suicide thoughts/attempts, $9(8.3 \%)$ patients answered 1 ("I have thoughts of killing myself, but I would not carry them out"), and 8 (7.4\%) answered 2 ("I would like to kill myself").

The most frequent reported symptoms of depression were changes in sleeping patterns $(N=66 ; 61.1 \%)$, tiredness or
Table 1 Descriptive characteristics of the sample

\begin{tabular}{|c|c|}
\hline $\begin{array}{l}\text { Characteristics } \\
N=117\end{array}$ & $N(\%)$ \\
\hline $\mathrm{Age}^{\mathrm{a}}$ & $M=53.05( \pm 19.69)$ \\
\hline$<30$ & $18(16.36)$ \\
\hline $30-40$ & $15(13.63)$ \\
\hline $41-50$ & $20(18.18)$ \\
\hline $51-60$ & $13(11.81)$ \\
\hline$>60$ & $44(40)$ \\
\hline \multicolumn{2}{|l|}{ Sex } \\
\hline Males & $56(47.9)$ \\
\hline Females & $61(52.1)$ \\
\hline \multicolumn{2}{|l|}{ Epilepsy duration } \\
\hline$\leq 12$ months & $19(17.8)$ \\
\hline 13 months -10 years & $51(47.7)$ \\
\hline$>10$ years & 37 (34.6) \\
\hline \multicolumn{2}{|l|}{ Epilepsy etiology } \\
\hline Structural & $51(46.4)$ \\
\hline Unknown & $44(40)$ \\
\hline Genetic & $8(7.3)$ \\
\hline Autoimmune & $2(1.8)$ \\
\hline Metabolic & $2(1.8)$ \\
\hline Encephalopathic & $2(1.8)$ \\
\hline Infective & $1(.9)$ \\
\hline \multicolumn{2}{|l|}{ Seizure type } \\
\hline Generalized & $43(39.1)$ \\
\hline Focal & $40(36.4)$ \\
\hline Mixed & $27(24.5)$ \\
\hline \multicolumn{2}{|l|}{ Seizure frequency ${ }^{\mathbf{b}}$} \\
\hline Seizure-free & $84(76.4)$ \\
\hline 1 episode & $17(15.5)$ \\
\hline$\geq 2$ episodes & $9(8.2)$ \\
\hline \multicolumn{2}{|l|}{ ASM } \\
\hline 1 & $78(70.9)$ \\
\hline $2-3$ & $32(29.1)$ \\
\hline Psychotropic drugs & $26(23.6)$ \\
\hline No psychotropic & $84(76.4)$ \\
\hline drugs & \\
\hline
\end{tabular}

${ }^{a}$ Age represents age at time of entry into the data

${ }^{\mathrm{b}}$ Seizure frequency in the last 28-day period before visit

fatigue $(N=66 ; 61.1 \%)$, and loss of energy $(N=66$; $61.1 \%$ ). Single-item response rates for female and male participants are displayed in Table 2.

\section{Gender differences}

Analysis on group comparison showed no significant differences between females and males on epilepsy-related characteristics (see Table 3). 
Table 2 Items scores frequencies observed in the two groups and in the total sample

\begin{tabular}{|c|c|c|c|c|c|c|c|c|c|}
\hline \multirow[t]{2}{*}{ BDI-II items } & \multicolumn{3}{|c|}{ Females $(n=57)$} & \multicolumn{3}{|c|}{ Males $(n=51)$} & \multicolumn{3}{|c|}{ Total $(n=108)$} \\
\hline & $\begin{array}{l}\text { Score } 0 \\
n(\%)\end{array}$ & $\begin{array}{l}\text { Score } 1 \\
n(\%)\end{array}$ & $\begin{array}{l}\text { Score 2-3 } \\
n(\%)\end{array}$ & $\begin{array}{l}\text { Score } 0 \\
n(\%)\end{array}$ & $\begin{array}{l}\text { Score } 1 \\
n(\%)\end{array}$ & $\begin{array}{l}\text { Score 2-3 } \\
n(\%)\end{array}$ & $\begin{array}{l}\text { Score } 0 \\
n(\%)\end{array}$ & $\begin{array}{l}\text { Score } 1 \\
n(\%)\end{array}$ & $\begin{array}{l}\text { Score 2-3 } \\
n(\%)\end{array}$ \\
\hline 1. Sadness & $\begin{array}{l}29 \\
(50.9 \%)\end{array}$ & $\begin{array}{l}21 \\
(36.8 \%)\end{array}$ & $\begin{array}{l}7 \\
(12.3 \%)\end{array}$ & $\begin{array}{l}40 \\
(78.4 \%)\end{array}$ & $\begin{array}{l}11 \\
(21.6 \%)\end{array}$ & $\begin{array}{l}0 \\
(0 \%)\end{array}$ & $\begin{array}{l}69 \\
(63.9 \%)\end{array}$ & $\begin{array}{l}32 \\
(29.6 \%)\end{array}$ & $\begin{array}{l}7 \\
(6.5 \%)\end{array}$ \\
\hline 2.Pessimism & $\begin{array}{l}28 \\
(49.1 \%)\end{array}$ & $\begin{array}{l}15 \\
(26.3 \%)\end{array}$ & $\begin{array}{l}14 \\
(24.6 \%)\end{array}$ & $\begin{array}{l}32 \\
(62.7 \%)\end{array}$ & $\begin{array}{l}14 \\
(27.5 \%)\end{array}$ & $\begin{array}{l}5 \\
(9.8 \%)\end{array}$ & $\begin{array}{l}60 \\
(55.6 \%)\end{array}$ & $\begin{array}{l}29 \\
(26.9 \%)\end{array}$ & $\begin{array}{l}19 \\
(17.6 \%)\end{array}$ \\
\hline 3.Past failure & $\begin{array}{l}35 \\
(61.4 \%)\end{array}$ & $9(15.8 \%)$ & $13(22.8 \%)$ & $\begin{array}{l}42 \\
(82.4 \%)\end{array}$ & $6(11.8 \%)$ & $\begin{array}{l}3 \\
(5.9 \%)\end{array}$ & $\begin{array}{l}77 \\
(71.3 \%)\end{array}$ & $\begin{array}{l}15 \\
(13.9 \%)\end{array}$ & $\begin{array}{l}16 \\
(14.8)\end{array}$ \\
\hline 4.Loss of pleasure & $\begin{array}{l}25 \\
(43.9 \%)\end{array}$ & $\begin{array}{l}18 \\
(31.6 \%)\end{array}$ & $14(24.6 \%)$ & $\begin{array}{l}31 \\
(60.8 \%)\end{array}$ & $\begin{array}{l}17 \\
(33.3 \%)\end{array}$ & $\begin{array}{l}3 \\
(5.9 \%)\end{array}$ & $\begin{array}{l}56 \\
(51.9 \%)\end{array}$ & $\begin{array}{l}35 \\
(32.4 \%)\end{array}$ & $\begin{array}{l}17 \\
(15.8 \%)\end{array}$ \\
\hline 5.Guilty feelings & $\begin{array}{l}31 \\
(54.4 \%)\end{array}$ & $\begin{array}{l}21 \\
(36.8 \%)\end{array}$ & $\begin{array}{l}5 \\
(8.8 \%)\end{array}$ & $\begin{array}{l}40 \\
(78.4 \%)\end{array}$ & $\begin{array}{l}11 \\
(21.6 \%)\end{array}$ & $\begin{array}{l}0 \\
(0 \%)\end{array}$ & $\begin{array}{l}71 \\
(65.7 \%)\end{array}$ & $\begin{array}{l}32 \\
(29.6 \%)\end{array}$ & $\begin{array}{l}5 \\
(4.6 \%)\end{array}$ \\
\hline 6.Punishment feelings & $\begin{array}{l}38 \\
(66.7 \%)\end{array}$ & $\begin{array}{l}8 \\
(14 \%)\end{array}$ & $\begin{array}{l}11 \\
(19.3 \%)\end{array}$ & $\begin{array}{l}42 \\
(82.4 \%)\end{array}$ & $\begin{array}{l}4 \\
(7.8 \%)\end{array}$ & $\begin{array}{l}5 \\
(9.8 \%)\end{array}$ & $\begin{array}{l}80 \\
(74.1 \%)\end{array}$ & $\begin{array}{l}12 \\
(11.1 \%)\end{array}$ & $\begin{array}{l}16 \\
(14.8 \%)\end{array}$ \\
\hline 7.Self-dislike & $\begin{array}{l}37 \\
(64.9 \%)\end{array}$ & $\begin{array}{l}15 \\
(26.3 \%)\end{array}$ & $\begin{array}{l}5 \\
(8.8 \%)\end{array}$ & $\begin{array}{l}42 \\
(82.4 \%)\end{array}$ & $\begin{array}{l}9 \\
(17.6 \%)\end{array}$ & $\begin{array}{l}0 \\
(0 \%)\end{array}$ & $\begin{array}{l}79 \\
(67.5 \%)\end{array}$ & $\begin{array}{l}24 \\
(22.2 \%)\end{array}$ & $\begin{array}{l}5 \\
(4.6 \%)\end{array}$ \\
\hline 8.Self-criticalness & $\begin{array}{l}38 \\
(66.7 \%)\end{array}$ & $\begin{array}{l}9 \\
(15.8 \%)\end{array}$ & $\begin{array}{l}10 \\
(17.6 \%)\end{array}$ & $\begin{array}{l}38 \\
(74.5 \%)\end{array}$ & $\begin{array}{l}5 \\
(9.8 \%)\end{array}$ & $\begin{array}{l}8 \\
(15.7 \%)\end{array}$ & $\begin{array}{l}76 \\
(70.4 \%)\end{array}$ & $\begin{array}{l}14 \\
(13 \%)\end{array}$ & $\begin{array}{l}18 \\
(16.7 \%)\end{array}$ \\
\hline 9.Suicidal thoughts/wishes & $\begin{array}{l}46 \\
(80.7 \%)\end{array}$ & $\begin{array}{l}6 \\
(10.5 \%)\end{array}$ & $\begin{array}{l}5 \\
(8.8 \%)\end{array}$ & $\begin{array}{l}45 \\
(88.2 \%)\end{array}$ & $\begin{array}{l}3 \\
(5.9 \%)\end{array}$ & $\begin{array}{l}3 \\
(5.9 \%)\end{array}$ & $\begin{array}{l}91 \\
(84.3 \%)\end{array}$ & $\begin{array}{l}9 \\
(8.3 \%)\end{array}$ & $\begin{array}{l}8 \\
(7.4 \%)\end{array}$ \\
\hline 10.Crying & $\begin{array}{l}25 \\
(43.9 \%)\end{array}$ & $\begin{array}{l}10 \\
(17.5 \%)\end{array}$ & $\begin{array}{l}22 \\
(38.6 \%)\end{array}$ & $\begin{array}{l}44 \\
(86.3 \%)\end{array}$ & $\begin{array}{l}3 \\
(5.9 \%)\end{array}$ & $\begin{array}{l}4 \\
(7.8 \%)\end{array}$ & $\begin{array}{l}69 \\
(63.9 \%)\end{array}$ & $\begin{array}{l}13 \\
(11.1 \%)\end{array}$ & $\begin{array}{l}26 \\
(24 \%)\end{array}$ \\
\hline 11.Agitation & $\begin{array}{l}24 \\
(42.1 \%)\end{array}$ & $\begin{array}{l}21 \\
(36.8 \%)\end{array}$ & $\begin{array}{l}12 \\
(21 \%)\end{array}$ & $\begin{array}{l}31 \\
(60.8 \%)\end{array}$ & $\begin{array}{l}19 \\
(37.3 \%)\end{array}$ & $\begin{array}{l}1 \\
(11.1 \%)\end{array}$ & $\begin{array}{l}55 \\
(50.9 \%)\end{array}$ & $\begin{array}{l}40 \\
(37 \%)\end{array}$ & $\begin{array}{l}13 \\
(12 \%)\end{array}$ \\
\hline 12.Loss of interest & $\begin{array}{l}33 \\
(57.9 \%)\end{array}$ & $\begin{array}{l}16 \\
(28.1 \%)\end{array}$ & $\begin{array}{l}8 \\
(5.9 \%)\end{array}$ & $\begin{array}{l}33 \\
(64.7 \%)\end{array}$ & $\begin{array}{l}15 \\
(29.4 \%)\end{array}$ & $\begin{array}{l}3 \\
(5.9 \%)\end{array}$ & $\begin{array}{l}66 \\
(61.1 \%)\end{array}$ & $\begin{array}{l}31 \\
(28.7 \%)\end{array}$ & $\begin{array}{l}11 \\
(10.2 \%)\end{array}$ \\
\hline 13.Indecisiveness & $\begin{array}{l}30 \\
(53.6 \%)\end{array}$ & $\begin{array}{l}13 \\
(23.2 \%)\end{array}$ & $\begin{array}{l}13 \\
(23.2 \%)\end{array}$ & $\begin{array}{l}30 \\
(60 \%)\end{array}$ & $\begin{array}{l}15 \\
(30 \%)\end{array}$ & $\begin{array}{l}5 \\
(10 \%)\end{array}$ & $\begin{array}{l}60 \\
(56.6 \%)\end{array}$ & $\begin{array}{l}28 \\
(26.4 \%)\end{array}$ & $\begin{array}{l}18 \\
(17 \%)\end{array}$ \\
\hline 14.Worthlessness & $\begin{array}{l}37 \\
(67.3 \%)\end{array}$ & $\begin{array}{l}13 \\
(23.6 \%)\end{array}$ & $\begin{array}{l}5 \\
(9.1 \%)\end{array}$ & $\begin{array}{l}39 \\
(79.6 \%)\end{array}$ & $\begin{array}{l}7 \\
(14.3 \%)\end{array}$ & $\begin{array}{l}3 \\
(6.1 \%)\end{array}$ & $\begin{array}{l}76 \\
(73.1 \%)\end{array}$ & $\begin{array}{l}20 \\
(19.2 \%)\end{array}$ & $\begin{array}{l}8 \\
(7.6 \%)\end{array}$ \\
\hline 15.Loss of energy & $\begin{array}{l}16 \\
(28.6 \%)\end{array}$ & $\begin{array}{l}21 \\
(37.5 \%)\end{array}$ & $\begin{array}{l}19 \\
(33.9 \%)\end{array}$ & $\begin{array}{l}24 \\
(48 \%)\end{array}$ & $\begin{array}{l}19 \\
(38 \%)\end{array}$ & $\begin{array}{l}7 \\
(14 \%)\end{array}$ & $\begin{array}{l}40 \\
(37.7 \%)\end{array}$ & $\begin{array}{l}40 \\
(37.7 \%)\end{array}$ & $\begin{array}{l}26 \\
(24.6 \%)\end{array}$ \\
\hline 16.Changes in sleeping pattern & $\begin{array}{l}14 \\
(25.5 \%)\end{array}$ & $\begin{array}{l}24 \\
(43.6 \%)\end{array}$ & $\begin{array}{l}17 \\
(30.9 \%)\end{array}$ & $\begin{array}{l}25 \\
(50 \%)\end{array}$ & $\begin{array}{l}21 \\
(42 \%)\end{array}$ & $\begin{array}{l}4 \\
(8 \%)\end{array}$ & $\begin{array}{l}39 \\
(37.1 \%)\end{array}$ & $\begin{array}{l}45 \\
(42.5 \%)\end{array}$ & $\begin{array}{l}21 \\
(20 \%)\end{array}$ \\
\hline 17.Irritability & $\begin{array}{l}23 \\
(41.1 \%)\end{array}$ & $\begin{array}{l}23 \\
(41.1 \%)\end{array}$ & $\begin{array}{l}10 \\
(17.9 \%)\end{array}$ & $\begin{array}{l}29 \\
(58 \%)\end{array}$ & $\begin{array}{l}18 \\
(36 \%)\end{array}$ & $\begin{array}{l}3 \\
(6 \%)\end{array}$ & $\begin{array}{l}52 \\
(49.1 \%)\end{array}$ & $\begin{array}{l}41 \\
(38.7 \%)\end{array}$ & $\begin{array}{l}13 \\
(12.3 \%)\end{array}$ \\
\hline 18.Changes in appetite & $\begin{array}{l}29 \\
(51.8 \%)\end{array}$ & $\begin{array}{l}16 \\
(28.6 \%)\end{array}$ & $\begin{array}{l}11 \\
(19.6 \%)\end{array}$ & $\begin{array}{l}32 \\
(64 \%)\end{array}$ & $\begin{array}{l}15 \\
(30 \%)\end{array}$ & $\begin{array}{l}3 \\
(6 \%)\end{array}$ & $\begin{array}{l}61 \\
(57.5 \%)\end{array}$ & $\begin{array}{l}31 \\
(29.2 \%)\end{array}$ & $\begin{array}{l}14 \\
(13.2 \%)\end{array}$ \\
\hline 19.Concentration difficulty & $\begin{array}{l}20 \\
(36.4 \%)\end{array}$ & $\begin{array}{l}20 \\
(36.4 \%)\end{array}$ & $\begin{array}{l}15 \\
(27.3 \%)\end{array}$ & $\begin{array}{l}24 \\
(48 \%)\end{array}$ & $\begin{array}{l}20 \\
(40 \%)\end{array}$ & $\begin{array}{l}6 \\
(12 \%)\end{array}$ & $\begin{array}{l}44 \\
(41.9 \%)\end{array}$ & $\begin{array}{l}40 \\
(38.1 \%)\end{array}$ & $\begin{array}{l}21 \\
(20 \%)\end{array}$ \\
\hline 20.Tiredness or fatigue & $\begin{array}{l}14 \\
(25 \%)\end{array}$ & $\begin{array}{l}23 \\
(41.1 \%)\end{array}$ & $\begin{array}{l}19 \\
(33.9 \%)\end{array}$ & $\begin{array}{l}26 \\
(52 \%)\end{array}$ & $\begin{array}{l}22 \\
(44 \%)\end{array}$ & $\begin{array}{l}2 \\
(4 \%)\end{array}$ & $\begin{array}{l}40 \\
(38.1 \%)\end{array}$ & $\begin{array}{l}45 \\
(42.5 \%)\end{array}$ & $\begin{array}{l}21 \\
(20 \%)\end{array}$ \\
\hline 21.Suicidal thoughts or wishes & $\begin{array}{l}30 \\
(56.6 \%)\end{array}$ & $\begin{array}{l}10 \\
(18.9 \%)\end{array}$ & $\begin{array}{l}13 \\
(23.2 \%)\end{array}$ & $\begin{array}{l}40 \\
(80 \%)\end{array}$ & $\begin{array}{l}6 \\
(12 \%)\end{array}$ & $\begin{array}{l}4 \\
(8 \%)\end{array}$ & $\begin{array}{l}70 \\
(68 \%)\end{array}$ & $\begin{array}{l}16 \\
(15.5 \%)\end{array}$ & $\begin{array}{l}17 \\
(16.5 \%)\end{array}$ \\
\hline
\end{tabular}

Results on depressive symptoms showed a significant gender difference in BDI-II total score $(U=791.5, p=000)$, with females reporting higher scores (mean rank $=65.55$ ) than males (mean rank $=41.15$ ). Compared with males, females 
rated the following items significantly higher: sadness $(U=$ $1014.500, p=.001)$, guilty feelings $(U=1076.500, p=.005)$, crying $(U=832.000, p=.000)$, loss of energy $(U=1013.000$, $p=.009)$, changes in sleeping pattern $(U=914.000, p=.001)$, tiredness or fatigue $(U=840.500, p=.000)$, loss of interest in $\operatorname{sex}(U=993.000, p=.008)$, and agitation $(U=1076.500, p=$ .010) (Figure 1).

The result on item 16 (changes in sleeping pattern) revealed that, overall, females reported more problematic sleep pattern as compared to males. The analysis of more frequent reported symptom about sleep impairment revealed that $29.5 \%(n=18)$ of females reported to sleep more than usual and that another same amount reported to sleep less than usual. Different results were observed in the male sample: $25 \%(n=14)$ showed to sleep less than usual and $16.1 \%(n=9)$ reported to sleep more than usual.

\section{The association between demographic and clinical characteristics and BDI-II score}

\section{Correlation analysis}

Results of Kendall correlation analysis showed significant and positive associations between age and generalized seizure, focal seizure, the presence of structured epilepsy, and the use of psychotropic drugs $(p<.01)$. Moreover, a negative correlation of age with unknown etiology of epilepsy was observed, suggesting that younger patients did not present evident causes of it. Epilepsy duration was correlated with the incremental use of ASM $(p<$ $.01)$, whereas BDI-II score was associated with female gender and the use of psychotropic drugs $(p<.01)$.

\section{Regression analysis}

The collinearity statistics (i.e., Tolerance and VIF) were all within acceptable limits [38], and an examination of the Mahalanobis distance scores [39] indicated no multivariate outliers. The hierarchical multiple regression revealed that the first step accounted for $13.2 \%$ of the variation in BDI-II, with gender contributing significantly to the regression model, $F(2,98)=7.439, p<.01$. At the second step, the introduction of clinical characteristics explained an additional $25.1 \%$ of

Table 3 Mann-Whitney $U$ test. Gender comparison on epilepsyrelated variables

\begin{tabular}{lll}
\hline Variable & $U$ & $p$ \\
\hline Epilepsy duration & 1014.500 & .212 \\
Epilepsy type & 1172.500 & .922 \\
Seizure type & 1125.500 & .212 \\
Seizure number & 1105.000 & .723 \\
ASM & 1076.500 & .431 \\
Psychotropic drugs & 1223.000 & .115 \\
\hline
\end{tabular}

variation in BDI-II, and this change in R2 was significant, $F$ $(13,87)=4.155, p<.001$.

A significant and negative regression coefficient was observed for epilepsy duration $>10$ years, indicating that longer epilepsy duration was associated with a lower BDI-II score. On the other hand, the use of psychotropic drugs and generalized seizures were independent positive determinants of depressive symptoms.

Moreover, a negative regression coefficient was observed for gender, indicating that females showed a trend towards being significantly associated with the BDI-II index. The predicted multiple regression model accounted jointly for $38.3 \%$ of the variation of the BDI-II (Table 4).

\section{Discussion}

The first aim of the present study was to examine the presence of depressive symptoms in patients with epilepsy visited in a tertiary clinical center, by using the BDI-II with a single-item analysis. This approach is appropriate to examine the distribution of individual item of the BDI-II providing additional information on the core features of depression among individuals with epilepsy [24].

Results showed that around $39 \%$ of participants reported clinically defined depressive symptoms, suggesting that an association between depression and epilepsy should be inferred. This finding is consistent with previous studies reporting similar percentage rates in Italian samples [23] and with the evidence on the frequency of depression in patients with epilepsy ranging from 9 to $37 \%$ [40]. Indeed, this wellknown variability of depressive symptoms reported by patients with epilepsy might be due to the heterogeneity of tools and methods employed to screen for depression in the published literature (e.g., self-reported scales, psychiatric interview; [41]). This variety often makes comparisons between studies impossible [40] thus being a barrier to understanding the relationship between depression and epilepsy.

The underling mechanisms explaining the epilepsydepression link highlight the contribution of both biological and psychosocial factors [42]. More specifically, the biological determinants of this association (e.g., hippocampal shrinking, amygdala hypertrophy) have been observed in neuroimaging and neurobiological studies and, similarly, the implication of psychological variables (e.g., stigmatization, coping mechanism) in the pathogenesis of depression in epilepsy has been also reported [43]. Epidemiological studies sustain a bidirectional relationship between epilepsy and depression, as depression may not only co-occur with and follow the onset of epilepsy [5] but also may increase the risk of developing this disease [44]. Overall, this evidence seems to suggest an underlying common neurobiological basis [45]. 
Fig. 1 Mean rank differences of each BDI-II item score between males and females

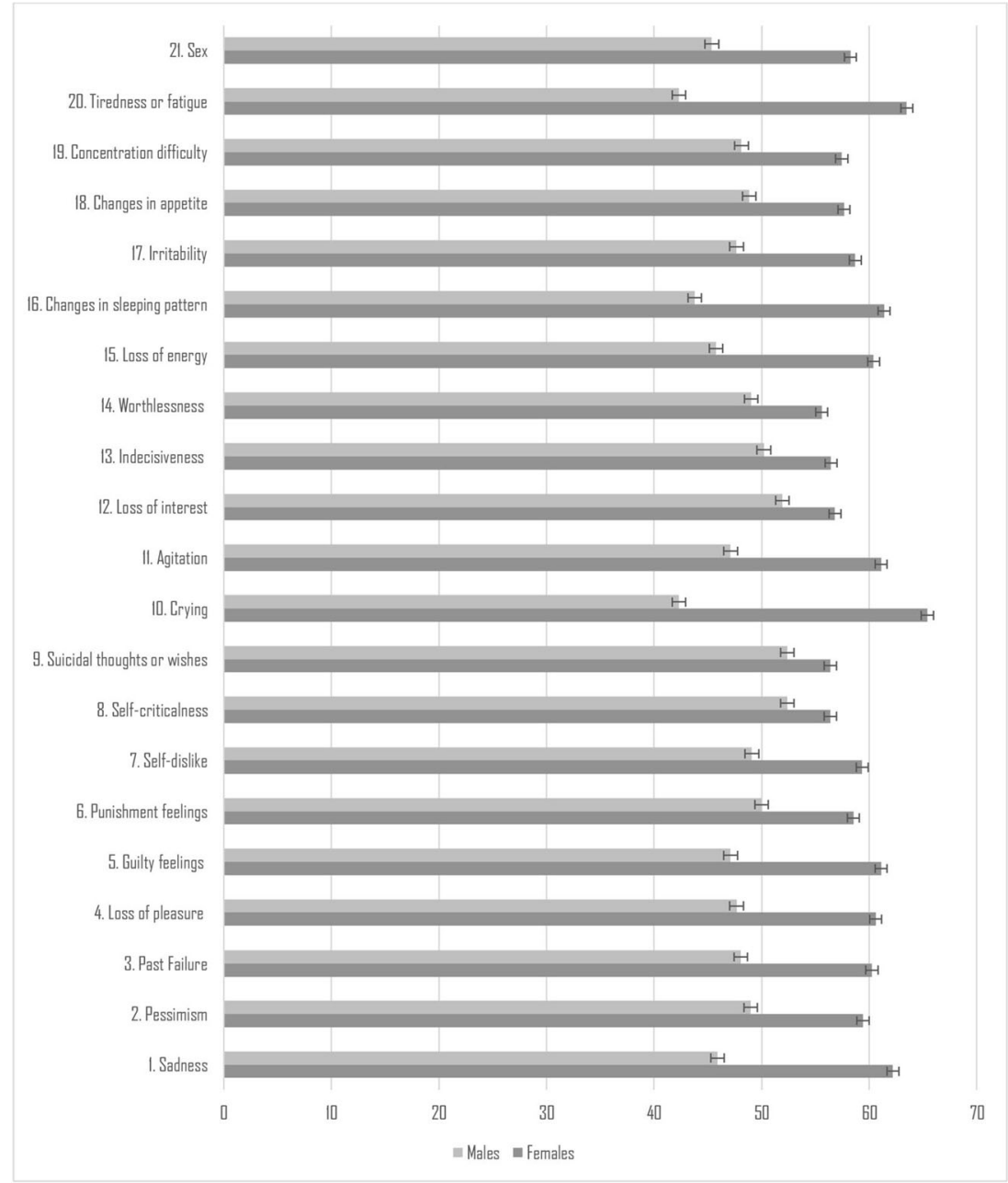

Results of the current study confirmed what was found in previous evidence [25], suggesting that depressive symptoms are more accentuated among female patients than male patients presenting epilepsy. Evidence on the general population suggests part of the gender gap might be explained by heightened exposure to severe adversity and by structural social gender inequity [46]. Consistently, gender was a significant and unique predictor of high BDI-II scores, above and beyond the clinical features of the sample. This evidence was consistent with results from gender comparison and reinforces the idea that being female is a strong depression-predisposing factor in epileptic patients [47]. A recent meta-analysis highlights that the female hormonal environment could be one explanation of this phenomenon, as the decrease in estrogen increases the likelihood of depression [8]. Furthermore, females typically face with challenging conditions that may be affected by epilepsy and significantly impact on their perceived quality of life, resulting in high negative emotionality. For example, an increased prevalence of depression during and after pregnancy in women with epilepsy as compared to women with other chronic diseases and women without epilepsy has been observed [47]. Also, some authors suggest that adverse effects of epilepsy (e.g., stigma, discrimination, vocational difficulties) may prevent the achievement of a job and cause depression in women [48]. Moreover, females may be more prone to disclosing depressive symptoms than men [8]. Therefore, future studies should assess factors possibly explaining the gender role in the depression-epilepsy association, and longitudinal research across the lifespan, examining risk factors and transdiagnostic outcomes, is needed.

The present study also examined the associations between depressive symptoms and demographic and clinical characteristics in patients with epilepsy. Differently from previous authors $[49,50]$ who found that a shorter epilepsy duration was significantly associated with a lower risk of depression, in the present investigation, high epilepsy duration was determined to decrease depression. This result is consistent with a previous study that found a negative correlation between epilepsy duration and BDI-II scores in patients with temporal lobe epilepsy [51]. A possible explanation for this rather contradictory result is that adults with long-term epilepsy "come to terms with their ailment over time" [52, p. 63]. In this context, it is noteworthy that a previous analysis of 99 adults suffering from intractable epilepsy found an association between longer 
Table 4 Summary of hierarchical regression analysis for variables predicting BDI-II total score

\begin{tabular}{llllllll}
\hline Variable & $\beta$ & $t$ & $\mathrm{sr}^{2}$ & $R$ & $R^{2}$ & $\Delta R^{2}$ \\
\hline Step 1 & & & & .363 & .132 & .132 \\
Gender & -.366 & -3.821 & -.360 & & & \\
Age & -.020 & -.211 & -.020 & & & \\
Step 2 & & & & .619 & .383 & .251 \\
Gender & -.333 & $-3.761^{* * *}$ & -.317 & & & \\
Age & -.081 & -.835 & -.070 & & & \\
Seizure frequency & & & & & & \\
One episode & -.054 & -.604 & -.051 & & & \\
$\geq 2$ episodes & .086 & .904 & .076 & & & \\
Number of ASM & & & & & & \\
ASM = 2 & -.044 & -.500 & -.042 & & & \\
ASM =3 & .173 & 1.834 & .154 & & & \\
Epilepsy duration & & & & & & \\
13 months-10 years & -.197 & -1.597 & -.134 & & & \\
$>$ 10 years & -.349 & $-2.694^{* * *}$ & -.227 & & & \\
Epilepsy type & & & & & & \\
Structured & .040 & .264 & .022 & & & \\
Unknown & .130 & .909 & .077 & & & \\
Seizure type & & & & & & \\
Generalized & .228 & $2.100^{*}$ & .177 & & & \\
Focal & -.055 & -.498 & -.042 & & & \\
Psychotropic drugs & .347 & $3.831^{* * *}$ & .323 & & & \\
\hline
\end{tabular}

Note: ${ }^{*} p<.05,{ }^{* *} p<.01,{ }^{* * *} p<.001$

duration of epilepsy and higher quality of life scores [53]. A long-term epilepsy may reflect a greater span of time available to face stressful difficulties brought about by this disease. Future studies on the current topic are therefore recommended in order to elucidate if perceived difficulties in coping with epilepsy-related disabilities (e.g., loss of independence) are associated with the duration of symptoms.

The positive unique association found in the present study between the use of psychotropic drugs and depression may indicate that patients with high severity of depression already received psychiatric medications. This finding reinforces the clinical supposition that psychiatric medications cannot present the same effectiveness in patients with epilepsy, thus justifying the need of personalized approaches, counting both pharmacological and non-pharmacological treatments, in patients with epilepsy taking into account that the disease per se can alter the neurobiological networks at the basis of depressive symptoms. Notably, the evidence that, among patients reporting depressive symptoms according to the BDI-II score, almost half (i.e., 57\%) did not already receive psychotropic medications might suggest that, in many cases, patients screened as positive for depression with this instrument are under-treated, consistently with previous observations [54]. This fact is not entirely unfavorable, considering the high rate of false positives for depression associated with the use of the BDI-II [55]. Conversely, it appeared that depressive symptoms can be overlooked in patients with epilepsy, in particular when the patients are seizure free. Further investigations should comply with the recommendation that the diagnosis of depression and the relative need of a treatment plan must be confirmed with a clinical interview conducted by a trained clinician [56].

The lack of associations with other epilepsy-related variables confirmed previous studies evidencing no significant changes in epilepsy characteristics (e.g., seizure frequency) in patients treated with antidepressants [57]. More specifically, in the present study, the seizure frequency was not associated with the severity of depression as indicated by regression coefficients. This result is confirmed by the evidence that the number of seizure-free patients in the current sample was very high (i.e., 76\%), thus suggesting that the high prevalence of depressive symptoms found (39\%) can only be partially explained by factors related to epilepsy. Previous authors suggested that epilepsy per se is related to the severity of depression, thus encouraging clinicians to treat all patients for depression irrespective of seizure frequency [54].

In the current sample, the presence of generalized seizure significantly predicted severity of depression. This result did not appear to corroborate previous evidence demonstrating that, in comparison to generalized seizures, focal seizures were associated with a higher risk of depressive symptoms [58]. On the other hand, this evidence substantiates previous findings in the literature indicating that patients diagnosed with generalized seizure are the most vulnerable to severe depression $[59,60]$.

The novelty of this study relies in the single-item analysis documenting that, among all the depressive symptoms, one of the most pronounced was changes in sleeping patterns, confirming that disrupted sleep patterns in epilepsy are commonly described clinically [61]. High percentage of patients also reported tiredness and loss of energy, suggesting that patients with epilepsy frequently experience extreme and persistent weakness or exhaustion [62]. Moreover, the high prevalence of all these symptoms may corroborate previous systematic evidence that sleep-related problems and fatigue are intercorrelated symptoms of depression in epileptic condition [9]. Future studies should extend the above single-item analysis to examine depressive symptoms in specific epilepsy type and in subgroups of patients (e.g., pediatric). Finally, the rate of suicide ideation (i.e., item 9) observed in the present sample (15.7\%) supported the prevalence of suicidal attempts found in previous evidence [63]. This finding encourages the development of appropriate suicide prevention strategies in conjunction with psychiatry and pharmacotherapy programs, especially considering that suicide is frequently underdiagnosed by physicians [64]. On the other hand, results concerning the depressive symptom rate in epilepsy should be interpreted with caution, since anergy, fatigue, and sleep disturbances are common symptoms reported by patients with epilepsy even in the absence of psychiatric conditions [9].

Some limitations are acknowledged in the present study including its cross-sectional nature, which does not allow 
demonstration of causal relationship between predictors and BDIII scores. Future studies should address this issue, especially considering that no clear results on a directional association exist. Some studies supported the relationship between depression symptom and epilepsy-related symptoms (e.g., seizure frequency) to be bidirectional [65]. On the other hand, depression appeared to be a prospective predictor for seizure frequency [66]. Further prospective studies are needed to fill this gap. Another limitation was the relatively small sample size, which might had affected the conclusions of the study in terms of their generalizability. Moreover, the application of subjective self-report instruments to assess depressive symptoms did not permit the exclusion of social desirability in the responses given by participants. Finally, the lack of a control group enabled the comparison between patients with epilepsy and healthy participants on depressive scores.

\section{Conclusions}

Despite the aforementioned limitations, the current study strengthens the imperative to screen for depression in epilepsy condition. Results suggested that female gender, short epilepsy duration, the use of psychotropic drugs, and generalized seizure were significantly associated with the severity of depression. Evidence on prevention and early diagnosis are still lacking $[67,68]$ and future treatment protocols focused on depression in epilepsy condition should account for the major trending observed in women.

Author contribution All authors contributed to the study conception and design. Material preparation and data collection were performed by Claudio Liguori, and analysis was performed by Mariacarolina Vacca. The first draft of the manuscript was written by Mariacarolina Vacca and all authors commented on previous versions of the manuscript. All authors read and approved the final manuscript.

\section{Code availability Not applicable.}

Funding Open access funding provided by Università degli Studi di Roma Tor Vergata within the CRUI-CARE Agreement. This study was partially supported by a grant funded to F.P. and N.B.M. from AIFA (FARM12PW7R/A6).

Data availability The datasets generated during and/or analyzed during the current study are available from the corresponding author on reasonable request.

\section{Declarations}

Ethics approval Approval was obtained from the ethics committee of University Hospital of Rome Tor Vergata (R.S. 191/17 - 192/17; Eudract 2017-000990-35). The procedures used in this study adhere to the tenets of the Declaration of Helsinki.
Consent to participate Informed consent was obtained from all individual participants included in the study.

Consent to publish Patients signed informed consent regarding publishing their data.

Competing interests The authors declare no competing interests.

Open Access This article is licensed under a Creative Commons Attribution 4.0 International License, which permits use, sharing, adaptation, distribution and reproduction in any medium or format, as long as you give appropriate credit to the original author(s) and the source, provide a link to the Creative Commons licence, and indicate if changes were made. The images or other third party material in this article are included in the article's Creative Commons licence, unless indicated otherwise in a credit line to the material. If material is not included in the article's Creative Commons licence and your intended use is not permitted by statutory regulation or exceeds the permitted use, you will need to obtain permission directly from the copyright holder. To view a copy of this licence, visit http://creativecommons.org/licenses/by/4.0/.

\section{References}

1. Mlinar S, Petek D, Cotič Ž et al (2016) Persons with epilepsy: between social inclusion and marginalisation. Behav Neurol 2016. https://doi.org/10.1155/2016/2018509

2. Rai D, Kerr MP, McManus S et al (2012) Epilepsy and psychiatric comorbidity: a nationally representative population-based study. Epilepsia 53:1095-1103. https://doi.org/10.1111/j.1528-1167. 2012.03500.x

3. Weatherburn CJ, Heath CA, Mercer SW et al (2017) Physical and mental health comorbidities of epilepsy: Population-based crosssectional analysis of 1.5 million people in Scotland. Seizure 45: 125-131. https://doi.org/10.1016/j.seizure.2016.11.013

4. Kanner AM, Balabanov A (2002) Depression and epilepsy: how closely related are they? Neurology 58:S27-S39. https://doi.org/10. 1212/WNL.58.8_suppl_5.S27

5. Josephson CB, Lowerison M, Vallerand I et al (2017) Association of depression and treated depression with epilepsy and seizure outcomes: a multicohort analysis. JAMA Neurol 74:533-539. https:// doi.org/10.1001/jamaneurol.2016.5042

6. Gaitatzis A, Trimble MR, Sander JW (2004) The psychiatric comorbidity of epilepsy. Acta Neurol Scand 110:207-220. https://doi. org/10.1111/j.1600-0404.2004.00324.x

7. Robertson MM Mood disorders associated with epilepsy. In: In: Psychiatry co-morbidity in epilepsy. American Psychiatric Press, Washington, pp 133-167

8. Kim M, Kim Y-S, Kim D-H et al (2018) Major depressive disorder in epilepsy clinics: a meta-analysis. Epilepsy Behav 84:56-69. https://doi.org/10.1016/j.yebeh.2018.04.015

9. Kwon O-Y, Ahn HS, Kim HJ (2017) Fatigue in epilepsy: a systematic review and meta-analysis. Seizure 45:151-159. https://doi.org/ 10.1016/j.seizure.2016.11.006

10. Moon H-J, Seo J-G, Park S-P (2016) Perceived stress and its predictors in people with epilepsy. Epilepsy Behav 62:47-52. https:// doi.org/10.1016/j.yebeh.2016.06.038

11. de Araújo Filho GM, Gomes FL, Mazetto L et al (2012) Major depressive disorder as a predictor of a worse seizure outcome one year after surgery in patients with temporal lobe epilepsy and mesial temporal sclerosis. Seizure 21:619-623. https://doi.org/10.1016/j. seizure.2012.07.002 
12. Scott AJ, Sharpe L, Hunt $C$ et al (2017) Anxiety and depressive disorders in people with epilepsy: a meta-analysis. Epilepsia 58: 973-982. https://doi.org/10.1111/epi.13769

13. Campos-Fernández D, Fonseca E, Olivé-Gadea M et al (2020) The mediating role of epileptic seizures, irritability, and depression on quality of life in people with epilepsy. Epilepsy Behav 113:107511. https://doi.org/10.1016/j.yebeh.2020.107511

14. Miller JM, Kustra RP, Vuong A et al (2008) Depressive symptoms in epilepsy. Drugs 68:1493-1509. https://doi.org/10.2165/ 00003495-200868110-00003

15. Besag FM (2004) Behavioural effects of the newer antiepileptic drugs: an update. Expert Opin Drug Saf 3:1-8. https://doi.org/10. 1517/14740338.3.1.1

16. Mula M, Sander L (2007) Negative effects of antiepileptic drugs on mood in patients with epilepsy. Drug Saf Int J Med Toxicol Drug Exp 30:555-567. https://doi.org/10.2165/00002018-20073007000001

17. Seethalakshmi R, Krishnamoorthy ES (2007) Depression in epilepsy: phenomenology, diagnosis and management. Epileptic Disord 9:1-10

18. Gill SJ, Lukmanji S, Fiest KM et al (2017) Depression screening tools in persons with epilepsy: a systematic review of validated tools. Epilepsia 58:695-705. https://doi.org/10.1111/epi.13651

19. Beck AT (1961) An inventory for measuring depression. Arch Gen Psychiatry 4:561. https://doi.org/10.1001/archpsyc.1961. 01710120031004

20. de Oliveira GN, Lessa JMK, Gonçalves AP et al (2014) Screening for depression in people with epilepsy: comparative study among neurological disorders depression inventory for epilepsy (NDDI-E), Hospital Anxiety and Depression Scale Depression Subscale (HADS-D), and Beck Depression Inventory (BDI). Epilepsy Behav 34:50-54. https://doi.org/10.1016/j.yebeh.2014.03.003

21. Beck AT, Steer RA, Brown G (1996) Beck Depression InventoryII. Psychol Assess. https://doi.org/10.1037/t00742-000

22. Assenza G, Lanzone J, Brigo F et al (2020) Epilepsy care in the time of COVID-19 pandemic in Italy: risk factors for seizure worsening. Front Neurol 11:737. https://doi.org/10.3389/fneur.2020. 00737

23. Tombini M, Assenza G (2020) Quintiliani L, et al Depressive symptoms and difficulties in emotion regulation in adult patients with epilepsy: association with quality of life and stigma. Epilepsy Behav 107:107073

24. Frisch C, Hanke J, Kleinerüschkamp S et al (2009) Positive correlation between the density of neuropeptide $\mathrm{Y}$ positive neurons in the amygdala and parameters of self-reported anxiety and depression in mesiotemporal lobe epilepsy patients. Biol Psychiatry 66:433-440. https://doi.org/10.1016/j.biopsych.2009.03.025

25. Fiest KM, Patten SB, Wiebe S et al (2014) Validating screening tools for depression in epilepsy. Epilepsia 55:1642-1650. https:// doi.org/10.1111/epi.12754

26. Hasin DS, Goodwin RD, Stinson FS et al (2005) Epidemiology of major depressive disorder: results from the National Epidemiologic Survey on Alcoholism and Related Conditions. Arch Gen Psychiatry 62:1097-1106. https://doi.org/10.1001/archpsyc.62.10. 1097

27. Fisher RS (2017) The new classification of seizures by the International League Against Epilepsy. Curr Neurol Neurosci Rep 17:48. https://doi.org/10.1007/s11910-017-0758-6

28. American Psychiatric Association (2000) Diagnostic and statistical manual of mental disorders, fourth edition, text revision. Author, Washington

29. Sica C, Ghisi M (2007) The Italian versions of the Beck Anxiety Inventory and the Beck Depression Inventory-II: psychometric properties and discriminant power. In: Leading-edge psychological tests and testing research. Nova Science Publishers, New York, pp $27-50$
30. McDonald RP (1999) Test theory: a unified treatment. Erlbaum, Hillsdale

31. Jones JE, Hermann BP, Woodard JL et al (2005) Screening for major depression in epilepsy with common self-report depression inventories. Epilepsia 46:731-735. https://doi.org/10.1111/j.15281167.2005.49704.x

32. Royston P (1992) Approximating the Shapiro-Wilk W-test for nonnormality. Stat Comput 2:117-119. https://doi.org/10.1007/ BF01891203

33. Perneger TV (1998) What's wrong with Bonferroni adjustments. Bmj 316:1236-1238. https://doi.org/10.1136/bmj.316.7139.1236

34. Nicolau J, Simó R, Conchillo C et al (2019) Differences in the cluster of depressive symptoms between subjects with type 2 diabetes and individuals with a major depressive disorder and without diabetes. J Endocrinol Investig 42:881-888. https://doi.org/10. 1007/s40618-019-01020-x

35. Abdi H (2007) The Kendall rank correlation coefficient. Encycl Meas Stat:508-510

36. Khamis H (2008) Measures of association: how to choose? J Diagn Med Sonogr 24:155-162. https://doi.org/10.1177/ 8756479308317006

37. Morgan GA, Barrett KC, Leech NL et al (2019) IBM SPSS for Introductory Statistics: use and interpretation. Routledge, 6th Edition

38. Miles J (2014) Tolerance and variance inflation factor. In: Balakrishnan N, Colton T, Everitt B et al (eds) Wiley StatsRef: Statistics Reference Online. John Wiley \& Sons, Chichester

39. De Maesschalck R, Jouan-Rimbaud D, Massart DL (2000) The Mahalanobis distance. Chemom Intell Lab Syst 50:1-18. https:// doi.org/10.1016/S0169-7439(99)00047-7

40. Kwon O-Y, Park S-P (2014) Depression and anxiety in people with epilepsy. J Clin Neurol Seoul Korea 10:175-188. https://doi.org/10. 3988/jen.2014.10.3.175

41. Snyder S, Strain JJ, Wolf D (1990) Differentiating major depression from adjustment disorder with depressed mood in the medical setting. Gen Hosp Psychiatry 12:159-165

42. Lin JJ, Mula M, Hermann BP (2012) Uncovering the neurobehavioural comorbidities of epilepsy over the lifespan. Lancet 380:1180-1192. https://doi.org/10.1016/S0140-6736(12) 61455-X

43. Mula M, Schmitz B (2009) Review: depression in epilepsy: mechanisms and therapeutic approach. Ther Adv Neurol Disord 2:337344. https://doi.org/10.1177/1756285609337340

44. Hesdorffer DC, Ishihara L, Mynepalli L et al (2012) Epilepsy, suicidality, and psychiatric disorders: a bidirectional association. Ann Neurol 72:184-191. https://doi.org/10.1002/ana.23601

45. Błaszczyk B, Czuczwar S (2016) Epilepsy coexisting with depression. Pharmacol Rep 68:1084-1092. https://doi.org/10.1016/j. pharep.2016.06.011

46. Kuehner C (2017) Why is depression more common among women than among men? Lancet Psychiatry 4:146-158. https://doi.org/10. 1016/S2215-0366(16)30263-2

47. Beghi E, Roncolato M, Visonà G (2004) Depression and altered quality of life in women with epilepsy of childbearing age. Epilepsia 45:64-70. https://doi.org/10.1111/j.0013-9580.2004. 56502.x

48. Bjørk, M. H., Veiby, G., Reiter, S. C., Berle, J. Ø., Daltveit, A. K., Spigset, O., ... \& Gilhus, N. E. (2015). Depression and anxiety in women with epilepsy during pregnancy and after delivery: a prospective population-based cohort study on frequency, risk factors, medication, and prognosis. Epilepsia, 56(1), 28-39.

49. Oguz A, Kurul S, Dirik E et al (2002) Relationship of epilepsyrelated factors to anxiety and depression scores in epileptic children. J Child Neurol 17:37-40. https://doi.org/10.1177/ 088307380201700109 
50. Yang Y, Yang M, Shi Q et al (2020) Risk factors for depression in patients with epilepsy: a meta-analysis. Epilepsy Behav 106: 107030. https://doi.org/10.1016/j.yebeh.2020.107030

51. Sarkis RA, Pietras AC, Cheung A et al (2013) Neuropsychological and psychiatric outcomes in poorly controlled idiopathic generalized epilepsy. Epilepsy Behav 28:370-373. https://doi.org/10.1016/ j.yebeh.2013.05.020

52. Canuet L, Ishii R, Iwase $M$ et al (2009) Factors associated with impaired quality of life in younger and older adults with epilepsy. Epilepsy Res 83:58-65. https://doi.org/10.1016/j.eplepsyres.2008. 09.001

53. Szaflarski M, Meckler JM, Privitera MD et al (2006) Quality of life in medication-resistant epilepsy: the effects of patient's age, age at seizure onset, and disease duration. Epilepsy Behav 8:547-551. https://doi.org/10.1016/j.yebeh.2006.01.001

54. Slot M, Sodemann M, Gabel C, Holmskov J, Laursen T, Rodkjaer L (2015) Factors associated with risk of depression and relevant predictors of screening for depression in clinical practice: a crosssectional study among HIV-infected individuals in D enmark. HIV med 16(7):393-402

55. Smarr KL, Keefer AL (2011) Measures of depression and depressive symptoms: Beck depression Inventory-II (BDI-II), center for epidemiologic studies depression scale (CES-D), geriatric depression scale (GDS), hospital anxiety and depression scale (HADS), and patient health Questionnaire-9 (PHQ-9). Arthritis Care Res 63(S11):S454-S466

56. Rodin G, Katz M, Lloyd N, Green E, Mackay JA, Wong R (2006) The management of depression in cancer patients: a clinical practice guideline. In: Program in Evidence-based Care (PEBC). Cancer Care, Ontario

57. Pisani F, Oteri G, Costa C et al (2002) Effects of psychotropic drugs on seizure threshold. Drug Saf 25:91-110. https://doi.org/10.2165/ 00002018-200225020-00004

58. Greenlee BA, Ferrell RB, Kauffman CI et al (2003) Complex partial seizures and depression. Curr Psychiatry Rep 5:410-416. https://doi.org/10.1007/s11920-003-0076-3
59. Owolabi SD, Owolabi LF, Udofia O et al (2016) Depression in patients with epilepsy in Northwestern Nigeria: Prevalence and clinical correlates. Ann Afr Med 15:179-184. https://doi.org/10. 4103/1596-3519.194279

60. Sezibera V, Nyirasafari D (2013) Incidence of depression in Epilepsy patients. Rwanda J 1:67-77. https://doi.org/10.4314/rj. v1il.5F

61. Maganti R, Sheth RD, Hermann BP et al (2005) Sleep architecture in children with idiopathic generalized epilepsy. Epilepsia 46:104 109. https://doi.org/10.1111/j.0013-9580.2005.06804.x

62. Hernandez-Ronquillo L, Moien-Afshari F, Knox K et al (2011) How to measure fatigue in epilepsy? The validation of three scales for clinical use. Epilepsy Res 95:119-129. https://doi.org/10.1016/ j.eplepsyres.2011.03.010

63. Jones JA, Hermann BP, Barry JJ et al (2003) Rates and risk factors for suicide, suicidal ideation, and suicide attempts in chronic epilepsy. Epilepsy Behav 4(Suppl 3):S31-S38. https://doi.org/10. 1016/j.yebeh.2003.08.019

64. Verrotti A, Cicconetti A, Scorrano B et al (2008) Epilepsy and suicide: pathogenesis, risk factors, and prevention. Neuropsychiatr Dis Treat 4(2):365. https://doi.org/10.2147/ndt.s2158

65. Thapar A, Roland M, Harold G (2005) Do depression symptoms predict seizure frequency — or vice versa? J Psychosom Res 59: 269-274. https://doi.org/10.1016/j.jpsychores.2005.04.001

66. Dehn LB, Pfäfflin M, Brückner S et al (2017) Relationships of depression and anxiety symptoms with seizure frequency: Results from a multicenter follow-up study. Seizure 53:103-109. https:// doi.org/10.1016/j.seizure.2017.11.008

67. Mula M (2017) Depression in epilepsy. Curr Opin Neurol 30(2): 180-186. https://doi.org/10.1097/WCO.0000000000000431

68. Schachter SC (2004) Epilepsy: major advances in treatment. Lancet Neurol 3(1):11

Publisher's note Springer Nature remains neutral with regard to jurisdictional claims in published maps and institutional affiliations. 